\title{
Den Gesundheitsschutz im Visier
}

\author{
Eine neue, von der Umgebungsluft unabhängige Atemschutzhaube gewährleistet beim Lackieren \\ eine hohe Atemluftqualität und zeichnet sich durch einen hohen Atemkomfort aus.
}

Die Gefahren, die beim Arbeiten mit Lacken von Farbpartikeln, Isocyanaten und organischen Lösemitteln ausgehen, werden häufig unterschätzt. Gesundheitsschäden machen sich zwar erst 10 bis 15 Jahre später bemerkbar, sind dann aber meist irreparabel. In Lackierbetrieben besteht daher die Pflicht, qualifizierte Atemschutzgeräte zu verwenden.

\section{Schutz bis zum 100-fachen TRK-Wert}

Die Atemschutzhaube von Sata (Sata air vision 5000) ermöglicht eine kabinenexterne Versorgung mit reiner Luft. Das Atemschutzsystem ist von der Umgebungsluft unabhängig und gewährleistet eine hohe Atemluftqualität ohne den Lackierer durch gesättigte Filter für lackkontaminierte Kabinenluft zu gefährden. Der fehlende Einatemwiderstand sorgt zudem für einen hohen Atemkomfort.

Die Luftversorgung funktioniert mittels Sicherheits-Druckluftschlauch. Der erhöhte Luftvolumenstrom erzeugt einen leichten Überdruck in der Haube und verhindert dadurch das Eindringen von Overspray oder Dämpfen. Ein akustisches Signal warnt, falls die Luftmenge unter den Sollwert sinkt. Das Gerät schützt bis zum 100-fachen TRK-Wert und ist für Dauereinsätze geeignet.

\section{Angenehmes und sicheres Arbeiten}

Die Haube ist für fast jede Kopfform geeignet und kann in Umfang, Höhe und Lage individuell eingestellt werden. Für mehr Sicherheit befindet sich an der Kopfdecke ein Stoßschutz. Das große Visier erlaubt einen Blickwinkel von $220^{\circ}$ und die lösemittelresistente Schutzfolie sorgt für eine reflektionsfreie Sicht. Durch die neue Atemluftverteilung wird die Luftströmung und damit der Geräuschpegel auf $64 \mathrm{~dB}$ reduziert. //

\section{Kontakt}

Sata GmbH \& Co. KG

Kornwestheim

Tel. 071548110

info@sata.com, www.sata.com

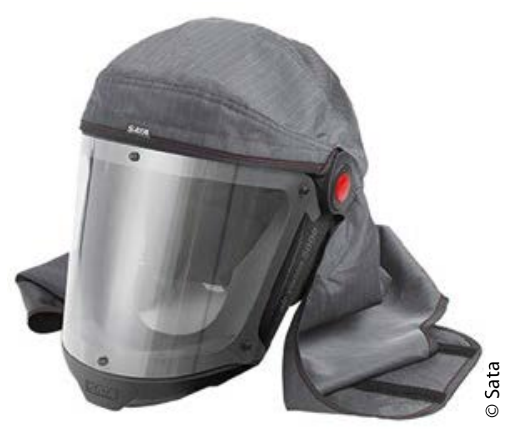

Die Atemschutzhaube ermöglicht eine kabinenexterne Versorgung mit reiner Luft.

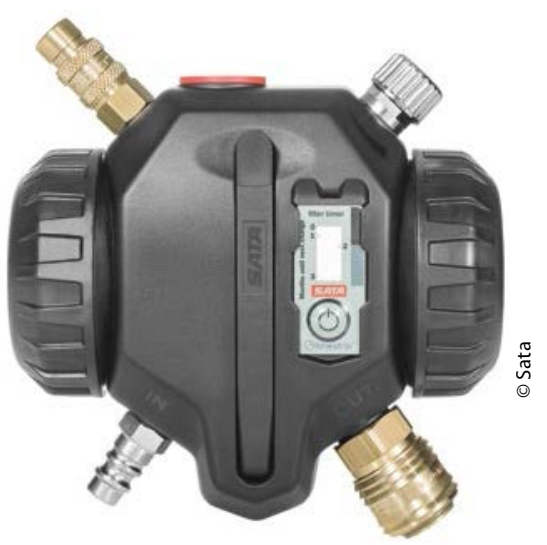

Die Luftversorgung funktioniert mittels Sicherheits-Druckluftschlauch. Der erhöhte Luftvolumenstrom erzeugt einen leichten Überdruck in der Haube und verhindert dadurch das Eindringen von Overspray oder Dämpfen. 